\title{
DE ALMUDENA Y SU LENGUAJE
}

El habla de Almudena es caso excepcional, no sólo en Misericordia, sino en la obra entera de Benito Pérez Galdós, y no porque no haya en ella otros personajes con parecidos rasgos de exotismo o torpeza idiomática, sino por tratarse de una figura principal -las otras no lo son- cuya lengua "áspera y dificultosa" (p. 35$)^{1}$ se nos transcribe con especial abundancia. El novelista se ha aplicado intensamente a hacer vivir a Almudena a través de su extraño lenguaje, ya haciéndonoslo oír directamente, ya en eficacísimas fusiones con el del narrador.

Aparte del propio Galdós ${ }^{2}$, no faltan comentaristas que hayan destacado la dificultad de precisar el origen y composición de este lenguaje ${ }^{3}$. Cuando Fradejas Lebrero afirma que es ésa una lengua creada por el novelista, que deliberadamente deforma el español ${ }^{4}$, no contradice, en el fondo, la observación de Ángel del Río sobre la presencia, en el habla de Almudena, de efectivos rasgos judeo-españoles ${ }^{5}$. Por eso, no es posible seguir a Fradejas en su opinión de que "nada tiene de español arcaico": bien a la vista están ciertos elementos característicos del español arcaizante de los sefardíes ${ }^{6}$, jun-

${ }^{1}$ Las páginas correspondientes a la novela misma (Edición Nelson, París, 1951) irán entre paréntesis en el texto.

2 "Prefacio del autor", op. cit., especialmente pp. 6-7.

3 Ángel del Río, nota preliminar a su edición de Misericordia, en colaboración con McKendree Petty, New York, 1946; José Fradejas Lebrero, "Para las fuentes de Galdós", RLit, 4 (1953), 319-344; L. B. Walton, Pérez Galdós and the Spanish novel of the nineteenth century, New York, 1927.

${ }_{4}$ "Su lenguaje amorfo y monstruoso nada tiene de español arcaico[...], y es una lengua ficticia, que aposta estropea el español" (art. cit., p. 339).

5 Del Río señala "the arbitrary personal speech of the Moorish beggar Almudena, in which Galdós has created a delightful ironic language, using some distinctive features of archaic Spanish, especially that of the Sephardic Jews" (op. cit., p. xxiv). Cf. Walton, op. cit., p. 209, nota 2: Almudena es un moro que habla "a curious jargon of his own".

${ }^{6}$ Por ejemplo siguro (passim), dicir (passim); güena (passim); diptongos analógicos, normales entre sefardíes, como quierer (passim), a los que agrega Galdós por su cuenta, aún con más frecuencia, formas como paliabra (p. 114), priebar 'probar' (p. 215); el yeísmo ocasional: cameio (p. 127), cabaiero (p. 211), 
to con muchos otros inventados por Galdós, cosa que no rechaza del Río. Si para un crítico este lenguaje es "monstruoso" y para el otro "deliciosamente irónico", ambos coinciden en que es, fundamentalmente, creación original del escritor.

Más difícil acaso que la cuestión de ese español o cuasi-español inventado es la del supuesto idioma natal de Almudena ${ }^{7}$. El interés que por el ciego manifiesta otro personaje de Misericordia, aquel clérigo "algo arabista y hebraizante, que solía echar algún párrafo con él, no tanto por caridad como por estudio" (pp. 274-275)-como si una especie de doble del Galdós prologuista se hubiera introducido en la novela-, haría suponer que Almudena hablaba uno de esos idiomas, si no los dos. Pero la realidad textual es que el ciego sólo revela recuerdos infantiles de ambas lenguas y del sefardí: la "melopea arábiga" que canta a Benina (pp. 253 y 357), la oración hebrea "Semá Israel Adonai Elohino 8 Adonai Ishat", que es lo único que le oímos decir correctamente (p. 116), y las "oraciones hebraicas en castellano del siglo $\mathrm{xv}$, que en la memoria desde la infancia conservaba" (p. 256). En la violenta escena del capítulo 23 en que el ciego, celoso del pobre Frasquito Ponte, llega a maltratar a Benina, Almudena siente en seguida grave remordimiento, se golpea la cara, se tira de los pelos y lanza "exclamaciones guturales en lengua arábiga" que la vieja no entiende (p. 212). En otra ocasión, cuando ella pide a Almudena que le busque un duro, "algo dijo el ciego en su extraña lengua que Benina tradujo por la palabra «imposible» [...]" (p. 48). Extraña e impenetrable es, pues, la lengua materna de Almudena ${ }^{9}$.

yorando (p. 219). Por otro lado, uso inconsecuente de formas verbales (de lo cual no hay que inferir, sin más, inconsecuencia en Galdós): querer (pp. 112, 210), quirier (p. 211), querier (p. 224), quierer (passim) y el uso extraño de pronombres, ajeno a una persona que supiera sefardí: "dirnos migo con tú" (p. 217) y otros. Debe observarse que, en general, el pronombre sigue al verbo; que suele faltar el complemento indirecto; pero que se da la forma preposicional sin que aparezca la preposición misma: "dicir tí secreto" (p. 112), "dar tí tuda" (p. 114), etc., y que muchas veces se emplea el pronombre complemento en lugar del pronombre sujeto: "Cuando querer tí", "Mi sabier cómo" (p. 112).

7 C. Bernaldo de Quirós llama la atención sobre el origen berberisco de la lengua del Sus, donde "apenas se habla el árabe" (Yebala y el bajo Lucus, Madrid, 1914, p. 289, n. 1, según R. Ricard, "Note sur la genèse de l'Aita Tettauen de Galdós", $\mathrm{BHi}, 37,1935$, p. 473, nota 1). A lo cual observa Ricard, con razón, que "cette question[...] n'intéresse que secondairement l'histoire de Misericordia. Retenons simplement qu'elle n'est aussi simple qu'elle paraît".

8 Sic. La traducción francesa de Maurice Bixio (Paris, 190o) corrige Elohim, p. 89 .

9 No es ésta la única ocasión en que nos ayuda Benina a entender al ciego, ni ocurre sólo con la "extraña lengua" de Almudena. Hay ejemplos de diálogo directo en que la vieja dice correctamente alguna palabra española estropeada por Almudena. Si no sabemos a qué atenernos cuando oímos la pregunta del 
En cambio, la que le "oímos" hablar directamente en la novela se puede reconocer con cierta precisión. Salvo cuando el ciego -al preguntarle la vieja en qué religión cree- declara ser eibrio (p. 113), Benina entiende, como nosotros, todo lo que él le dice. $Y$ en el caso de eibrio, sentimos que esta palabra, aun pronunciada correctamente, habría dejado perpleja a la buena mujer ${ }^{10}$.

Raros son en Misericordia los momentos en que el narrador se interpone para facilitarnos la tarea de comprensión explicando en buen español lo que el ciego dice. En la descripción que éste hace a Benina (cap. 12) del complicadísimo procedimiento que ha de seguirse para obtener el tesoro del rey Samdai, el novelista mismo narra ciertas partes, pero sin llamar la atención sobre la necesidad de "traducir" - como sí hace en otros casos que luego veremos-, y con ese estilo indirecto combina los muy directos comentarios de Benina y trozos vivamente dialogados. Y no sólo en ellos, sino también en los de "discurso indirecto libre", introduce bastantes palabras al estilo de Almudena -bujeros 'agujeros' (pp. 115 y 116 ), carrash 'laurel', cabe 'cerca de' (p. 115), arregimientos (p. 118)-, procedimiento de evocación tan frecuente también en otras novelas de Galdós. Con análoga colaboración entre novelista y personaje se cuenta en los capítulos 13 y 14 la historia de la Petra y la del propio Almudena ${ }^{11}$.

mendigo "¿No tenier tú cosa que peinar?", nos lo aclara la respuesta de Benina: “...todo empeñado ya..." (p. 5 o).

${ }^{10}$ En la versión francesa no se presenta la dificultad creada por la pronunciación, pues Almudena dice claramente: "Je suis Hébreu" (p. 87). En general, el habla del ciego ofrece menos peculiaridades en esa traducción. La caracterizan el uso esporádico de infinitivos y las frases entrecortadas e incompletas. Aunque no parece que Galdós vigilara con mucho esmero la labor de Maurice Bixio, sí sabemos por su prólogo a la edición Nelson que estuvo en correspondencia con él: "muy a menudo me escribía consultándome las dificultades del léxico que a cada paso encontraba [...]. Contestábale yo satisfaciendo sus dudas en lo posible, no en todos los casos, pues yo mismo ignoro el sentir de algunos decires que de continuo inventan y ponen en circulación las bocas madrileñas" (p. 8). Con esa idea del habla popular, ¿̨no se habrá sentido Galdós autorizado a inventar también por su cuenta?

11 En lo que de la historia del ciego nos narra el autor, los "almudenismos" son los siguientes: muquier 'mujer' (p. 125); muquieres, mismo como vosotras ver migo (p. 126); baixo terra 'subterráneo', ilcienso 'incienso', cáñamo, el cameio 'camello', brancos 'blancos', mocha medo 'mucho miedo', medo, arregimiento, mochas, alcranes 'alacranes' (p. 127); medo, vido (p. 128); pieldras 'piedras', mochas, rubiles 'rubíes', tudas 'todas', diamanta fina, trompacios 'topacios' (cf. infra, nota 13), poño mio 'puño mío' (p. 129); baixo terra, por fanegas, muquier, pieldras, diniero, naida, la suya, arregimientos, tudo, ilcienso (p. 13o); $m u$ 'muy', olivares, "un pueblo [de Francia: Lille] que le llaman Lila" (p. 131). Recursos parecidos utiliza luego Galdós cuando relata los negocios de la Diega y la Petra, en que inserta palabras como comercianta (p. 133), y cuando explica, en el párrafo siguiente, las ideas y vagas ambiciones que esos negocios de compra y venta suscitan en Benina. Pero nótese que, al pasar de un personaje a 
II

No es ésa la forma en que trata Galdós a otros personajes suyos que, creados hacia la misma época de Almudena, hablan también un español chapurreado o no fácilmente comprensible. Uno de los ejemplos más interesantes es Churi Arratia, el de Luchana (1899), el joven que, a consecuencia de su sordera, vuelve a una extraña mezcla de vascuence y castellano. Churi es figura de cierta importancia en la novela, de un temple primitivo y fogoso que recuerda el de Almudena, aunque sus circunstancias son muy diversas. Su lenguaje se nos transmite por lo general en castellano, pero aquí y allí se nos dan muestras más directas, pintorescas por cierto, después que Galdós ha llamado la atención del lector sobre ellas. "De lo último que hablaron [Churi y Zoilo] se copia lo menos violento, dejando intraducidas y al natural las locuciones del maligno sordo"'12. Sigue un breve diálogo en que el muchacho sordo advierte a su primo que Aura no es para él, sino para el caballero madrileño: "Prinsipe arrecho vendrá él, y casarse hará con ella, y más... Al dimonio tú aquí mismo, y más. Eso dite, pues... ¿Qué harás si la tía Pudrencia saberlo ella?... ¿Para qué es desir? Murirte harás. . . Reírme yo. .. dite qué patuo eres, patuo y parol"'13. Y poco después, respondiendo a las interrogadoras miradas de su familia, ansiosa de saber quiénes han caído en la batalla entre carlistas e isabelinos, dice: "¿Yo qué saber? Diez y siete muertos de Mallona sacar. . Yo verlos. No estar Zoilo; ninguno muerto de los diez y siete es él mismo... Más no sé"14.

Ambos pasajes recuerdan vagamente, no sólo al quijotesco Sancho de Azpeitia, sino a Almudena, con su staccato habitual, su abuso

otro, Galdós matiza cuidadosamente las formas que subraya. Al comercianta de la Petra, corresponde en Benina negociante (subrayado también, para marcar el contraste).

12 Luchana (Episodios nacionales, $3^{\mathrm{a}}$ serie), Madrid, 1900, p. 208.

13 Ibid. Cruces humorísticos semejantes a Pudrencia aparecen en el habla de Almudena, o en la narración de Galdós que la imita: trompacios (p. 129) y requesito 'requisito' (p. 218), que Almudena ha oido antes de labios de Benina (p. 116). En la misma p. 218, Benina dice una vez requisito y otra requesito.

${ }_{14} O p$. cit., p. 223. Parecida es el habla de un personaje incidental, Chomin, en Zumalacárregui. También aquí se trata de un vasco que habla castellano: "En el camino de Elosua, los cristinos. .. ; muchos, muchos. .. ; caballería grande... Detenerse para ración... Pasar hacen por aquí bajo... hacia Azcoitia, pues" (Episodios nacionales, $3^{\text {a }}$ serie, Madrid, 1904, pp. 99-100). Comp. asimismo esta conversación entre dos mujeres vascas, en la misma novela: "-Ya se fueron, pues, con tropa. Volver ya harán, pues, a las diez. La cena ya pedirle han hecho a Casiana. - Chapelgorris dormir hacen por la noche..., y algunas noches ya hemos visto, pues, subir monte y hablar confianza con partidas" (p. 106). Una vieja anima a sus compañeros a tirar de un pesado cañón, monte arriba: "¿Cansar hacéis? Aquí no cansar ninguno. Pensar, pues, que a rastra lleva el mismo religión, y quitar el de herejes... Pensar esto, pues, y Dios ya dará fuerzas a vos, hará que fuerzas tener como bueyes y caballos..." (pp. 1og-110). 
de infinitivos, sus transposiciones de pronombres. En el primero de esos trozos, según hemos visto, Galdós se ha propuesto deliberadamente evocar de algún modo el especial sabor del habla de Churi. Si el lector se queda sin entender tal o cual palabra, tanto da. Lo que importa no son las palabras por sí mismas. De cuando en cuando el novelista vuelve a referirse al creciente silencio de Churi y a sus dificultades de expresión cada vez mayores. Su "vascuence mal castellanizado, que es forzoso traducir" (Luchana, p. 364 ), aparece en fuerte contraste con el ardor y con la intensidad y abundancia de pensamiento que caracterizan al personaje.

En un Episodio algo posterior, Las tormentas del 48 (1902), una enferma dice en "fugaces, desconcertadas, infantiles expresiones: -Tero agua..., tero mimir ['dormir']..., daca mano tuya..." Su amigo, el narrador, entra entonces a transcribir con sus propias palabras el resto de la conversación: "Con modulaciones sólo por mí entendidas decíame que le limpiara la boca del agua que bebía, la frente del sudor, y que no quitase de su cuello el brazo mío que le servía de almohada"15. También en Narváez (1902), el narrador, Pepe García Fajardo, ayuda al lector a comprender el lenguaje de un mendigo: "reproduzco textualmente el informe, componiendo a mi modo la sintaxis, y supliendo las sílabas comidas". Y bien claro está que necesitamos los auxilios del traductor cuando oímos decir a Gambito: "Nor, Cigüela. . . viento. .. sus. . . llagas”, que Fajardo se decide "a traducir" como "Lucila está en el convento de Jesús", pero sin saber a ciencia cierta a quién se refieren esas "llagas"'16.

En ocasiones, tropezamos con la dificultad de los dialectos regionales, como el valenciano en La campaña del Maestrazgo (1899). Urdaneta - se nos cuenta- "no sacó nada en limpio" al preguntar dónde estaban y cómo se llamaba el pueblo" ${ }^{17}$. Aparte de las formas dialectales utilizadas en el diálogo, Galdós las incrusta a veces por su cuenta, principalmente en sus pasajes descriptivos: "Los caragols ['rizos'] sobre las sienes", "los arcaicos polques ['arracadas valencianas'] de oro" (p. 129), mas 'cortijo' (passim), masonero 'dueño de cortijo' (pp. 278 y 295). Tanto Aita Tettauen (1904-05) como Carlos VI en la Rápita (1905) abundan en diálogo y expresiones sueltas sefardíes, presentadas en general con bastante fidelidad, aunque pueda señalarse tal cual descuido (sephardim utilizado como singular, en Carlos VI..., pp. 31, 34 y 76). Galdós se muestra favorable, en conjunto, al judeo-español, y ciertos personajes, como Yohar, hablan un muy correcto castellano ${ }^{18}$.

15 Episodios nacionales, $4^{\text {a }}$ serie, Madrid, 1902, p. 234.

16 Episodios nacionales, $4^{\text {a }}$ serie, Madrid, 1902, pp. 295, 339.

17 Episodios nacionales, $3^{\text {a }}$ serie, Madrid, 19oo, p. I1 1.

18 Carlos VI en la Rápita y Aita Tettauen, Episodios nac., $4^{\text {a }}$ serie, Madrid, 1905. Ejemplo del habla de los sefardíes que encuentra Santiuste en Tetuán es 
Si el propósito de Galdós hubiera sido, pues, hacer de su Almudena un simple moro o judío africano, nada le habría impedido tratar su lenguaje como en las novelas que acabamos de citar. $\mathrm{O}$ bien, si el personaje que quería Galdós retratar hubiera sido de lengua compleja y difícil, pero sin que su hablar mismo desempeñase función importante en la obra, habría podido recurrir a procedimientos mixtos o elusivos como los antes mencionados. Es evidente que acierta Robert Ricard cuando observa en su excelente artículo sobre Almudena ${ }^{19}$ que el mendigo es uno de los muchos personajes ambiguos de las novelas de Galdós (p. 12), que es al parecer una combinación de realidad y fantasía (pp. 14 y 2o) y que constituye un doble símbolo (p. 22), como en seguida veremos. Pero los símbolos de Galdós no suelen pecar de vaguedad - por el contrario, corren el riesgo de ser jay! demasiado claros-, y hasta sus ambigüedades o ambivalencias están, las más de las veces, bien a la vista ${ }^{20}$. Los dos símbolos son, para Ricard, el del semitismo (doble a su vez, puesto

el de Mazaltob, "hebrea viuda de más que mediana edad" que "trafica en bálsamos por ella misma compuestos": "-Te he llamado para decirte que la otra mañana, estando yo en prado de Almorain arrecogiendo herbas, topé a un mancebo ferido, que me demandó agasajo... Yo, lastimosa, le truje a mi casa, aonde me dijo ser español. Su nombre es Juan el Pacificante, y tie semblán de profeta... Anda en perdicación de la paz, y del campo cristiano echáronle por sus perdicas, y agora viene acá para que aproclamemos la paz y no la guerra... Él es bueno, es sencillo, y el habla tiene bonica española, que adulza el oído. Entra y verásle" (pp. 206-207). Y Mohamed Requema "habla regularmente el español..." (p. 229). Cf. también el elogio que hace Galdós del habla de Esther Morton, y del judeo-español en general, en Gloria: "Era [Esther Morton] además española por la lengua, pues desde la cuna aprendió a hablar como Nebrija. Sabido es que todas las familias israelitas que proceden de las expulsiones españolas conservan su lengua, aunque adulterada por la falta de renovación" (Primera parte, Madrid, 19o8, pp. 268-269). Y sigue: "El que viaje oor tierras donde viven judeo-españoles oye hablar un castellano arcaico, que produce en el ánimo dulce y melancólica sorpresa, cual si oyera un eco de la patria pasada y muerta[...]. Los hebreo-españoles[...] conservan la lengua de sus mayores" (p. 269). En La de los tristes destinos Galdós trata con la misma simpatía al dueño de un negocio modesto de ropa hecha y usada, el cual se da cuenta de que su cliente es un español emigrado en Londres que no sabe inglés: “...con afabilidad humilde le soltó esta frase: - «Señor, ¿topa lo que le place?n Ibero le miró; creía escuchar una voz que venía del tiempo de los Reyes Católicos; y así erạ, en efecto. El jndío siguió hablando con él en la jerga que llaman judeoespañol. Había oído Santiago que existían en diferentes partes del mundo hebreos de procedencia hispana que conservaban en sus hogares como reliquia preciosa la lengua de Castilla, y alegróse de comprobar por sí mismo el fenómeno" (Episodios nacionales, 4a serie, Madrid, 1907, p. 261).

19 "Sur le personnage d'Almudena dans Misericordia", $B H i$, 61 (1959), 12-25.

20 Un ejemplo muy sencillo es el de los personajes cuyos nombres tienen sentido doble, según se les vea con ironía o sin ella: Doña Perfecta, Don Inocencio. (O las "dos caras" de la parroquia de San Sebastián: Misericordia, p. 17). 
que comprende lo hebreo y lo musulmán) y el de la tolerancia (p. 22). Es como si Galdós volviera al tema de Gloria, por muy distintas que las dos obras sean (p. 24), y el hispanista francés sugiere: "También es posible que el gran novelista haya querido evocar aquellos tiempos lejanos de la historia española en que estas tres religiones coexistían en su tierra como existen en la persona de Almudena, judío, musulmán y bautizado"' (p. 25).

Todo eso es muy posible. Lo que aquí desearíamos ver es cómo tales posibilidades adquieren en Misericordia su forma precisa. Ante todo, Galdós se complace en señalar su deuda al modelo "arrancado del natural por una feliz coincidencia", ese "ciego andrajoso, que por su facha y lenguaje parecía de estirpe agarena”. El prólogo -escrito en 1919, dieciséis años después de la novela- subraya la intención escrupulosamente realista del narrador: "hube de emplear largos meses en observaciones y estudios directos del natural"; "Toda la verdad del pintoresco Mordejai es obra de él mismo, pues poca parte tuve yo en la descripción de esta figura"; "la documentación laboriosa que reuní". Resulta curioso, pues, que ese mismo Mordejai que en el curso de la novela declarará ser de religión hebrea aparezca oblicuamente clasificado en el prólogo, por su figura y por su "español aljamiado", como musulmán. El novelista lo confirma con una bien clara referencia a la prohibición mahometana de beber vino: "Le llevé conmigo por las calles céntricas de Madrid, con escala en varias tabernas donde le invité a confortar su desmayado cuerpo con libaciones contrarias a las leyes de su raza". Las libaciones de Almudena no serían, en cambio, contrarias a su religión, pero Galdós no alude a ella, como si la ignorara, como si volviese a colocarse a sí mismo en los primeros instantes de su trato con el pintoresco mendigo, en que tanto asombro le causaban todavía la "salvaje rudeza de aquel infeliz" y los "juramentos terroríficos" con que éste interrumpe su promesa de contarle su vida y milagros ${ }^{21}$. El prologuista ha escogido con astucia una parte del todo. En unas páginas en que con tanto empeño pondera la importancia decisiva del modelo, y el mucho tiempo y trabajo que el novelista ha dedicado a estudiarlo fotográficamente, Galdós construye con todo cuidado ese modelo a base de un super-modelo - iel Mordejai de la novela ya escrita!- en que él escoge unas notas y oculta otras, para no anticipar el sabroso misterio del personaje total.

¡Cuánto más complicado es, en efecto, nuestro Almudena-Mordejai, el de las canciones hebreas, arábigas y sefardies, que por un lado proclama a Adonai, "un Dios, uno solo, solo Él" (p. 255) y por otro aturde a Benina con los desvarios de su "oriental leyenda" ( $p$.

${ }^{21}$ Todas las frases entre comillas de este párrafo proceden del Prefacio de Pérez Galdós a la edición Nelson, pp. 5-7. 
119) y los ridículos conjuros con que pretende ganarse la voluntad del "Rey de baixo terra" (cap. 12)! Galdós nos tiene acostumbrados (como Cervantes) a la diversidad de los nombres y epítetos, pero éstos tienden a girar en torno al primitivo nombre del personaje $e^{22}$. No así en el caso de Almudena. Pues nuestra confusión aumenta cuando nos enteramos de que no es ése el nombre moro con que pudo habérsele conocido en su Sus originario, sino el nombre cristiano con que se le ha bautizado en España: José María de la Almudena (p. 255), o Joseph Marien Almudena, como dice él mismo (ibid.). Por muy escrupuloso que el escritor naturalista haya sido al "transcribir" el genio y figura del mendigo madrileño, nada nos invita a aceptar con demasiada literalidad sus declaraciones ${ }^{23}$. Ante todo, de haber respetado estrictamente el modelo, es probable que Galdós no hubiera hecho hablar árabe a un natural de Sus (véase supra, nota 7).

Por otra parte, entra aquí decisivamente en juego la expresa intención del novelista de prodigar en Misericordia "el lenguaje popular salpicado de idiotismos, elipsis y solecismos, tan donosos como pintorescos" (prefacio cit., p. 8), ya que en este libro su constante afán de "formar un mundo complejo, heterogéneo y variadísimo, para dar idea de la muchedumbre social en un periodo determinado de la Historia" (ibid.) se concentra especialmente en el Madrid ínfimo, en el de "la suma pobreza, la mendicidad profesional, la vagancia viciosa, la miseria, dolorosa casi siempre, en algunos casos picaresca o criminal" (ibid., p. 5). El abundante y colorido lenguaje de Almudena, lejos de desentonar, en Misericordia, del fondo idiomático de la obra entera, se apoya en él y es como su nota extrema y culminante. En libros anteriores, Galdós solía preferir la homogeneidad de un solo estilo narrativo. Recuérdense, en Gerona, los comentarios de Araceli cuando refunde por su cuenta el relato de Andresillo Marijuán para que "en su vasta longitud se hallase el trazo de una sola pluma"24.

22 Si nos limitamos a Misericordia, podemos señalar los de Benina, Benigna, Benina de Casia, Benigna de Casia, señá Benina, Nina; doña Francisca Juárez de Zapata, doña Francisca Juárez, doña Francisca, Francisca, la Francisca, doña Paca, Paquita Juárez, la viuda de Zapata; Francisco Ponte Delgado, el señor de Ponte y Delgado, el señor de Ponte Delgado, Frasquito Ponte, D. Frasquito, el Sr. D. Frasquito, el Sr. de Ponte, Frasquito, Ponte Delgado, Ponte, D. Frasco, el caballero Ponte.

23 Sobre esta duda, cf. Ricard, "Sur le personnage d'Almudena...", p. 21.

24 Sobre este punto, Araceli es muy explícito: "he modificado un tanto la relación de Andresillo Marijuán[...], pues su rudo lenguaje me causaba cierto estorbo al tratar de asociar su historia a las mías. Hago esta advertencia para que no se maravillen algunos de encontrar en las páginas que siguen observaciones, frases y palabras impropias de un muchacho sencillo y rústico. Tampoco yo me hubiera expresado así en aquellos tiempos; pero téngase presente que, en la época en que hablo, cuento algo más de ochenta años, vida suficiente a mi 


\section{IV}

Pero en Almudena las peculiaridades de lenguaje indican algo más que un deseo, en el escritor, de derrochar los "pintoresquismos" idiomáticos de un modelo de carne y hueso, que posee una exótica pero bien concreta lengua materna y que estropea el español. Si examinamos con atención el habla del mendigo, advertiremos que su rasgo más saliente, fuera de ciertas características de pronunciación -en que se nota a veces cierta inconsecuencia ${ }^{25}$-, es la falta, con pocas excepciones, de conjugación verbal y de flexión en los adjetivos. Predominan los infinitivos, participios, sustantivos y pronombres, sin sutilezas ni transiciones ni adornos: un habla desnuda y esencial que -haciendo pie en los modos convencionales de representar el español hablado por extranjeros- se ajusta al temple tumultuoso y exaltado del personaje. $Y$ aun hace Galdós que, tanto en sus rasgos de pronunciación como en los de vocabulario y sintaxis, refleje Almudena el habla vulgar que le rodea y en la cual se ha moldeado la suya. Véase esta muestra, del capítulo tercero:

- ¿Hablar vos del Piche? Conocierle mí. No ser marido la Casiana con casarmiento, por la luz bendita, no. Ser quirido, por la bendita luz, quirido.

-¿Conócesle tú?

- Conocierle mí, comprarmi dos rosarios él... de mi tierra dos rosarios, y una pieldra imán. Diniero él, mucho diniero... Ser capatazo de la sopa en el Sagriado Corazón de allá... y en toda la pobrieza de allá, mandando él, con garrota él... barrio Salamanca... capatazo... Malo, mu malo, y no dejar comer... Ser un criado del Goberno, del Goberno malo de Ispania, y de los del Banco, aonde estar tuda el diniero en cajas soterranas... Guardar él, matarnos de hambre él...

Si tanto nos divierte y conmueve este lenguaje, es, en no pequeña medida, porque reconocemos y saboreamos en él la original manera en que lo oído y aprendido se ha puesto al servicio de modos personalísimos de ser.

Ni el sentido se mutila u oscurece por obra de una sintaxis tan elemental. Lo que principalmente expresa Almudena son sus emo-

juicio para aprender alguna cosa, adquiriendo asimismo un poco de lustre en el modo de decir" (pp. 18-19). Y al acabar la historia: "Tal vez haya perdido mucho la leyenda de Andrés al perder la sencillez de su tosco estilo, pero yo tenía empeño en uniformar todas las partes de esta historia de mi vida, de modo que en su vasta longitud se hallase el trazo de una sola pluma" (Gerona, Madrid, 1889 , p. 244).

25 Véase supra, nota 6 . Además de querer y sus variantes, encontramos que con venir alternan viener, vinier, viner, venier y vinir; llorar y yorar; beno y güeno; tierra y terra, etc. 
ciones y deseos, y está bien claro que lo más de su sentir y querer gira en torno a Benina:

Voy a do quierer tú (p. 45).

Yo quierer ti... Si tú no quierer mí, Almudena matar sí él sigo (p. 214).

Matar yo galán bunito (p. 229).

Mí no comier... (p. 252).

Mí no triste[...] estar tigo contentado[...] yo quierer ti como ángela bunita... Y si no quierer tú casar migo, ser tú madra mía, y yo niño tuyo bunito (p. 360 ).

Almudena sólo responde a Benina, a la bondad, desde el principio hasta el fin. Pero ella responde a todos y a todo en el curso de la novela: marcha de polo a polo, desde el engaño, simulación y materialidad a que la obliga su devoción a doña Paca, cuando ésta necesita de su criada para sobrevivir, hasta la honradez y sinceridad de su vida con el mendigo ciego, hermano suyo espiritual, ahora totalmente entregado a su misericordia. Ciego, indigente, leproso, desposeído hasta de su propio pasado (la mayor parte de sus creencias y ritos hebraicos, y la lengua semítica, sea cual fuere, que haya podido saber), y sin elementos actuales de cultura que lo reemplacen, parece perdido en una desierta "tierra de nadie". Pero no. Donde vive es en una tierra de todos, guiado simplemente por su fe en un Dios único y en el amor al prójimo. Benina pertenece espiritualmente a este mismo reino, a pesar de ser cristiana, y ahí es donde ella y Almudena se encuentran y seguirán viviendo. No hay secreto, no hay misterio entre ellos, y esta sencillez y franqueza se nos transmite en su modo directo de hablar y de proceder, en la expresión ágil y exacta de Benina y en la incorrecta y apasionada de Almudena. Ningún otro personaje participa en estas privilegiadas afinidades electivas. A los otros les falta imaginación y les sobran palabras y fingimientos ${ }^{26}$. Sólo Frasquito Ponte llega fugazmente, en un instante de locura, al linde de ese reino, proclamando ángel a Benina y "caballero de la Arabia" a Almudena (pp. $3^{64}$ y 363 ).

A pesar de las limitaciones de Almudena y de las enormes diferencias que lo separan de Benina, él es, en la economía de la novela, una poderosa contraparte de la protagonista. Y se encuentra también en equilibrio y enlace con otros personajes menores, capaces a su vez, aunque en proporciones mucho más modestas que el ciego visionario, de ilusión y esperanza. La fantasía de Frasquito Ponte, vuelta hacia el pasado, puede hacerle ver en Obdulia toda una Emperatriz Eugenia. Más próxima a Benina, doña Paca no llega, sin embargo, más allá de un entresueño profético de la herencia que en efecto

26 Cf: "Sólo los entendimientos de ideas inseguras y de movedizo criterio propenden a la verbosidad" (Doña Perfecta, Madrid, 1878, p. 34). 
acabará por recibir. La imaginación de Benina es inmensamente más vivida y activa, y -como conviene, por otra parte, a su genial practicidad-culminará con la misteriosa invención de don Romualdo, que borrando mágicamente las fronteras de lo natural y lo sobrenatural, a ella misma la dejará atónita ${ }^{27}$. Pero Almudena, que es todo imaginación, que cree íntegramente en lo que imagina, va en busca de la mujer que el rey Samdai le ha prometido (p. 130), y no le sorprende hallarla, ni su ceguera física le impide reconocerla. El fervor de Almudena, la fusión (más intemporal que histórica) de sus religiones, o detritus de religiones, en una sola vivísima fe, necesita del apoyo de Benina, en quien el don de imaginar aparece combinado con un admirable buen sentido. Poco importa que Benina se sienta - y se diga - “ “. . con más años que San Isidro, y esta miseria y esta facha!" (p. 253). Si ella no quiere casarse con el ciego, éste será hijo suyo (p. 36o). Aun cuando recobrara la vista, como Pablo en Marianela, Almudena no confundiría apariencia y espíritu, no perdería nada. Ni tiene por qué padecer las dudas, y la lucha por alcanzar la verdad, que amargan al conde de Albrit en El abuelo. La verdad cabal de Benina se impone instantáneamente al mendigo, que se consagra a ella de la manera más primaria y absoluta.

Si las figuras de Benina y Almudena, en un primer plano, se iluminan y se dan mutuo relieve sin cortar sus lazos con el juego imaginativo de los otros personajes, Galdós se ha demorado con lujo de simpatía en la extraña lengua del ciego, haciendo de ella el colmo del "colorido poético" y de la "hipérbole graciosa" (p. 124), y haciendo también que desde él domine Almudena, a la vez en contraposición y enlace, el abigarrado coro del habla popular ambiente. Como en ningún otro personaje de Misericordia, el novelista ha subrayado en Almudena la expresiva gesticulación con que acompaña sus palabras (pp. 128, 120 y passim). Como en ningún otro, ha sometido a profunda elaboración sus pasajes de "estilo indirecto libre". Es corriente en Galdós, como en tantos narradores de los siglos xix y $\mathrm{xx}$, que los trozos de "discurso vivido" se contaminen de voces características del personaje mismo (cf. supra, nota 11). Este procedimiento, y la transposición de los tiempos verbales (en lugar de "Insistió Juliana en la recomendación: -Ya verá usted pronto la diferencia", Galdós escribe (p. 327): "Ya vería pronto la diferiencia"), son los habituales "indicios de estilo indirecto libre", como los llama Marguerite Lips"28. Pero en Misericordia se llega por ese camino a una complejidad, relieve y color incomparables. Véase la sabrosa combinación de los distintos modos de discurso en las primeras

27 Véase ahora Monroe Z. Hafter, "Ironic reprise in Galdós' novels", PMLA, 76 (1961), p. 239, y Leon Livingstone, "Interior duplication in the modern Spanish novel”, PMLA, 73 (1958), p. 399 .

28 Le style indirect libre, Paris, 1926, p. 187. 
páginas del capítulo 14 , donde, en un marco de lenguaje indirecto, resaltan vivísimas las palabras "textuales" y los comentarios exteriores e irónicos (pp. 126-127):

Explicó Almudena que distinguía las masas de obscuridad en medio de la luz: esto por lo tocante a las cosas del mundo de acá. Pero en lo de los mundos misteriosos que se extienden encima y debajo, delante y detrás, fuera y dentro del nuestro, sus ojos veían claro, cuando veían, mismo como vosotras ver migo. Bueno: pues se le aparecieron dos ángeles, y como no era cosa de aparecérsele para no decir nada, dijéronle que venían de parte del Rey de baixo terra con una embajada para él. El señor Samdai tenía que hablarle, para lo cual era preciso que se fuese mi hombre al Matadero por la noche, que se estuviese alli quemando ilcienso, y rezando en medio de los despojos de reses y charcos de sangre, hasta las doce en punto, hora invariable de la entrevista. No hay que añadir que los ángeles se marcharon con viento fresco.

$\mathrm{O}$, en el relato que sigue, obsérvese el variado juego de aproximación, refracción y distancia con que el novelista se apoya unas veces en pintorescas frases nominales ("Él, Mordejai, mocha medo, un medo que le quitaba el respirar[...] Cada vez más medo[...]", p. 127), resume otras veces por su cuenta ("Para no cansar[...]", p. 128, "Total: que a una orden del Rey le fueron poniendo delante todas aquellas bateas y canastos de oro[...]”, pp. 128-129), traslada luego su foco de atención a las tres mujeres que escuchan al mendigo "embobadas, mudas, fijos los ojos en la cara del ciego, entreabiertas las bocas" (p. 129) y, volviendo en fin a Almudena, remata el cuadro con unas pocas pinceladas magistrales: "Ponía toda su alma en su voz, y con la lengua hablaban todos los pliegues movibles de su cara, y hasta los pelos de su barba negra. Todo era signos, jeroglífico descifrable, oriental escritura que los oyentes entendían sin saber por qué” (p. 129).

Nada ha olvidado Galdós en su tarea de dar forma acabadísima a la expresión personal -lírica e irrefrenable- del misterioso mendigo. El prefacio querría asegurarnos, bajo palabra de escritor naturalista, que el habla de Almudena corresponde a un modo genérico y social de humanidad, bien localizable "en un período determinado de la Historia"; pero, por otra parte, Galdós se ha esforzado ahincadamente en labrar un lenguaje exclusivo, un mundo idiomático aparte que no conviene a ningún tipo histórico, a ningún papel genérico de árabe, ni de sefardí, ni de mendigo extranjero en Madrid, sino al individualísimo héroe de la fe y la imaginación pura en Misericordia: al único e inconfundible Mordejai, alias José María de la Almudena.

DeNAH LiDA

Brandeis University. 